\title{
The management effectiveness of protected areas in Kenya
}

\author{
Kenneth Otieno Onditi ${ }^{1,2,3,4}$ D $\cdot$ Xueyou $\mathrm{Li}^{1} \cdot$ Wenyu Song ${ }^{1,2} \cdot$ Quan $\mathrm{Li}^{1}$. \\ Simon Musila ${ }^{3,4}$. James Mathenge ${ }^{5}$. Esther Kioko ${ }^{3,4}$. Xuelong Jiang ${ }^{1,4}$
}

Received: 22 August 2020 / Revised: 9 August 2021 / Accepted: 23 August 2021 /

Published online: 13 September 2021

(C) The Author(s) 2021

\begin{abstract}
Merely designating new and/or expanding existing protected areas (PAs) does not guarantee the protection of critical ecosystems and species. The management of PAs must be effective to sustain meaningful conservational outcomes. We inferred the management effectiveness of PAs in Kenya based on the representation of ranges and distribution of multiple diversity dimensions of terrestrial mammals and their association with governance and designation types. We hypothesized that different governance types underlie variable management efficacies, such that stricter-managed PAs have better habitats that attract more wildlife, translating to higher species diversity compared to less strictly-managed PAs, especially for focal species groups (large carnivores, large herbivores, and endangered species). The results showed nearly all terrestrial mammals in Kenya represented in at least one PA. However, the relative proportion of represented ranges were low, and analysis of spatial conservation prioritization showed significant expansion beyond current PAs needed to achieve a one third coverage of focal species' ranges in a best-solution reserve system. Differences in PA governance and designation types were not systematically associated with diversity variances, and while there were more unique species in state-managed PAs than in privately-managed ones, averaged diversity coefficients were comparable between categories. Diversity variances explained by PA size and status year were low in a combined species pool but increased in focal species groups. These findings suggest that success in terrestrial mammal conservation in PAs in Kenya require clearly and formally streamlined definition, performance feedback, and collaboration terms between state-managed and privately-managed PAs.
\end{abstract}

Keywords Biodiversity conservation $\cdot$ Focal species $\cdot$ Kenya $\cdot$ Large mammals $\cdot$ Protected area $\cdot$ Protected area management

Communicated by Dirk Sven Schmeller.

Kenneth Otieno Onditi and Xueyou Li contributed equally.

This article belongs to the Topical Collection: Biodiversity protection and reserves.

Xuelong Jiang

jiangx1@mail.kiz.ac.cn

Extended author information available on the last page of the article 


\section{Introduction}

The global proliferation of protected areas (PAs) is an enduring means of combating biodiversity declines and was a commendable tool towards achieving Aichi Biodiversity Target 11 (Pimm et al. 2014; Ceballos et al. 2015; Saura et al. 2019; UNEP-WCMC and IUCN 2021b). Even so, the effectiveness of PAs in conserving biodiversity remains debated due to continued species declines and ecosystem degradations within them (Hockings et al. 2006; Craigie et al. 2010; Joppa et al. 2016). This has intensified realizations that merely designating new and/or expanding existing PAs does not guarantee the protection of ecosystems and species (Barnes 2015; Geldmann et al. 2019), rather, the PA management must be effective and equitable to guarantee meaningful long-term conservational success and viability. Evaluating such effectiveness remains integral to efforts towards curbing unnatural biodiversity declines (Coad et al. 2015).

With recent studies showing increasingly high proportions of wildlife occurring outside existing PAs and populations declining within PAs (Craigie et al. 2010; Ogutu et al. 2016), Kenya is among the countries where understanding whether and how PA management relate to biodiversity distributions and welfare is pertinent. The country boasts several PAs under different governance and designation types, denoting whether the government manages them through state-mandated bodies or whether they are managed privately by local communities, individuals, and for-/non-profit organizations (UNEP-WCMC and IUCN 2021a). The PAs managed by the state (SPAs) have a stricter approach due to policy frameworks and operational systems formalized through state laws while privately-managed PAs (PPAs) have a less strict approach with their operations and rights controlled by land tenure agreements with local communities, individuals, and the state (Carter et al. 2008). Different PA management and designation types also mirror variable political and community goodwill and funding surety (Ervin 2003; Carter et al. 2008; Stolton et al. 2017) which might lead to variable effectiveness of conservational success such as curbing poaching, deforestation, land encroachment, and pollution across PAs. In the process, nonrandomly variable ecological states and species diversity distribution patterns might emerge between PAs based on the management and designations differences (Geldmann et al. 2013). In particular, due to stricter implementation of restrictions against ecosystem degrading threats, SPAs likely maintain ideal habitats for most mammals, reciprocally translating to higher species richness and phylogenetic and functional diversity compared to PPAs (Wicander 2015; Munoz Brenes et al. 2018; Harris et al. 2019). Oberosler et al. (2020) observed that highly human-disturbed PAs had low species diversity and altered occurrence patterns compared to strictly managed PAs which were less disturbed. In contrast, the less strict restrictions to access by local communities in PPAs (Carter et al. 2008; Stolton et al. 2017) imply they might be less species-rich, especially for larger mammals that are more sensitive to humans (Riggio et al. 2018).

Across most sub-Saharan countries, the utilization of PAs for biodiversity conservation mainly targets large charismatic mammals which are fundamental to touristic attractions (a vital economic pillar in these countries), are a major attraction for donor funding, and significantly influence political and policy action (Maciejewski and Kerley 2014; Balmford et al. 2015; Muchapondwa and Stage 2015; Lindsey et al. 2020). The large mammals also serve as focal species, embodying the viability of species conservation in PAs due to their high sensitivity to human disturbance and extinction risk (Morrison et al. 2007; Caro 2010). Ecologically, most large mammals influence the functioning and integrity of ecosystems by driving the abundance, distribution, and diversity of other species (Soulé 
et al. 2005; Caro 2010). For instance, as top predators of large- and medium-sized herbivores, large carnivores drive herbivore population and distribution patterns while the feeding and movement of megafaunas such as elephants, rhinoceroses, and giraffes create new resources and habitats for other species (Duffy 2002; Lacher et al. 2019). Overall, the large and endangered mammals are good models for investigating distribution and diversity mechanisms in PAs concerning management and designation differences because they are globally endangered (Bowyer et al. 2019), surrogates of other wildlife's populations, and are highly diverse in terms of ecology, taxonomy, traits, and behaviour (Safi et al. 2011; Ripple et al. 2014; Bogoni et al. 2018).

For effective conservation practices, the metrics employed in evaluating the prioritization of areas and species should not only capture species richness but also the phylogenetic and functional dimensions (Devictor et al. 2010). Because species richness oversimplifies community assembly processes that determine the total taxa ecosystems can naturally support (Veech 2018), the use of phylogenetic diversity and functional diversity as complementary biodiversity indices rose in the early 1990s (Devictor et al. 2010; Chao et al. 2014). Various phylogenetic diversity and functional diversity indices can be decoupled into contrasting attributes to meaningfully target conservation of evolutionary diversity and species ecosystem functions (Faith 2016; Mazel et al. 2017, 2018; Cadotte and Tucker 2018; Edie et al. 2018). Measuring biodiversity using multidimensional diversity attributes also enable the conservational application of less obvious but useful biodiversity metrics such as the ratio of species representation and uniqueness in a local pool relative to a regional or global pool (Pärtel et al. 2013).

In this study, we analyzed the representation of terrestrial mammal ranges in PAs and how different PA governance and designation types relate to distribution patterns of multiple diversity dimensions. We hypothesized that diversity indices are not significantly variable between PA designation and management categorizations for the combined species pool but significant for focal species groups (large carnivores, large herbivores, and endangered species). We mainly sought to answer three questions; (i) How are the ranges and diversity of terrestrial mammals in Kenya represented in PAs? (ii) Do PA management and designation differences influence terrestrial mammal diversity distributions? and (iii) How do state-managed PAs compare with privately-managed ones in the representation of terrestrial mammal ranges and diversity distributions, especially of focal species (large carnivores, large herbivores, and endangered species)?

\section{Methods}

\section{Protected areas in Kenya}

We used the catalogue of PAs from the World Database on Protected Areas (UNEPWCMC and IUCN 2021a) whose records are the only comprehensive, up-to-date, and publicly available data on PAs in Kenya. We dropped PAs with no land overlap, leaving 400 PAs (Online Resource 1: ESM_1) which comprised five governance types; government, indigenous peoples, individual or community, local communities, and non-profit organizations, and six designation types; community conservancy, community nature reserve, forest reserve, national park, national reserve, and private reserve (Fig. 1). We considered SPAs as those managed by national or county governments while PPAs were those managed by non-governmental bodies-communities, indigenous people, for-profit and 

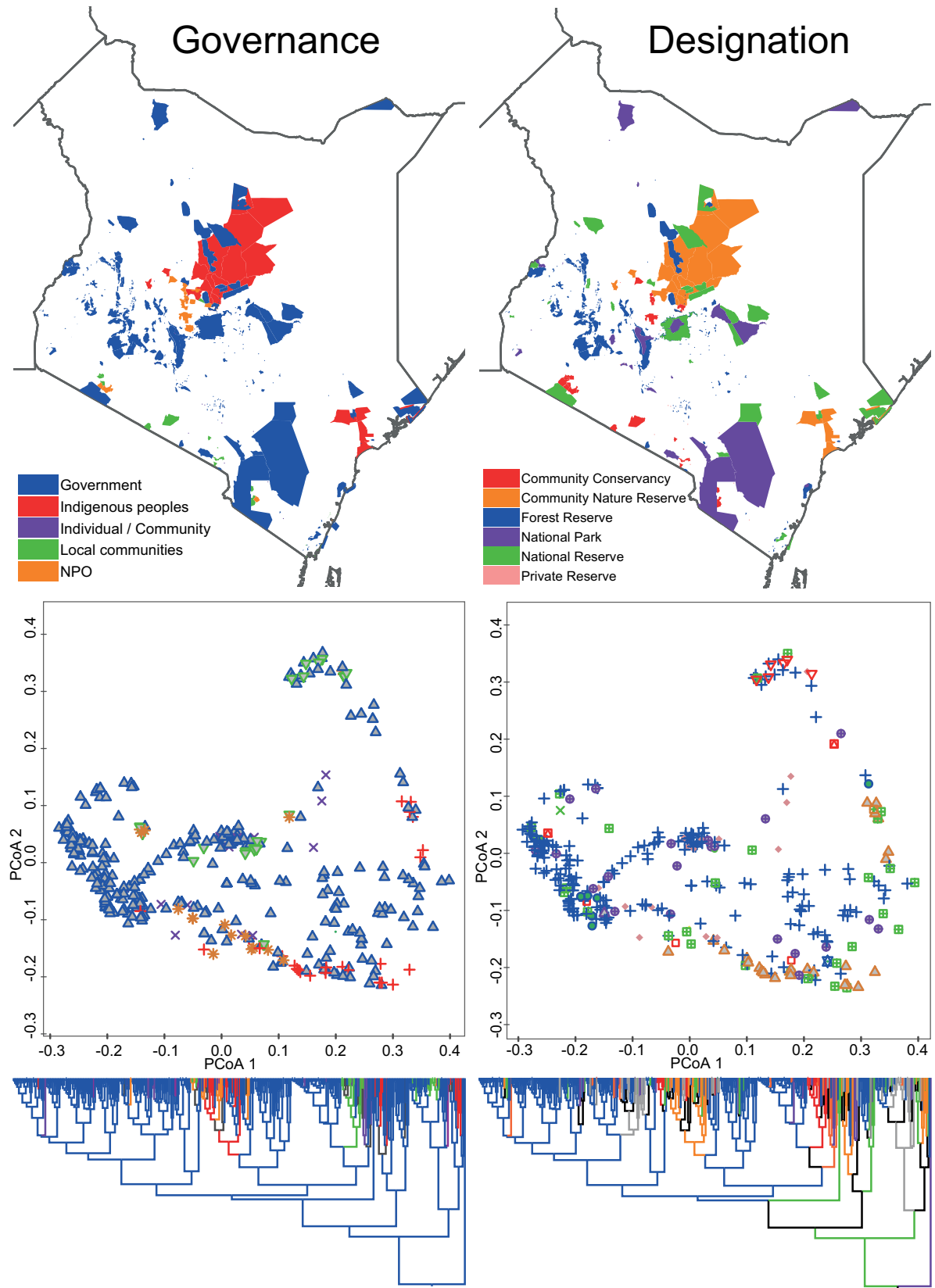

Fig. 1 The distribution of terrestrial mammals in protected areas in Kenya between management (Governance) and designation (Designation) types. The dendrograms and scatter plots represent the clustering of the PAs based on species composition dissimilarity (taxonomic dissimilarity). The maps, scatterplots, and dendrograms are shaded in corresponding colours 
non-profit organizations, and individuals. The strict SPAs were SPAs with forest reserves excluded. Based on PAs with spatial size reported, the SPAs comprised the bigger portion of the $12.4 \%$ land area considered protected compared to the PPAs ( $\approx 66 \%$ versus $\approx 34 \%$ ) (Online Resource 1: ESM_1). For the current study, we could not compile PA-level data on the mammal fauna composition in Kenya's PAs or accurate species-specific range data, as such, we relied on the representation of species ranges within PAs as a surrogate of their protection appraisal. While such representation might be a flawed appraisal of management effectiveness, it provides an important assessment of the state of Kenya's biodiversity (species and ecosystems) conservation progress (Chape et al. 2005).

\section{Species checklist and distribution data}

We used the checklist of Musila et al. (2019) as the backbone taxonomy of Kenya's mammals (Online Resource 1: ESM_2). The annotated checklist is the most recent and comprehensive synthesis of Kenya's mammals from existing taxonomic evaluations, revaluations, and new species descriptions. We obtained species distribution data from the International Union for Conservation of Nature [IUCN] red list of threatened species (UNEP-WCMC and IUCN 2021a) and the Global Biodiversity Information Facility (GBIF.org 2020). The distribution of missing species was resolved by geospatially referencing their distribution accounts in the literature to draw new layers which were then merged with the IUCN and Global Biodiversity Information Facility datasets into a single distribution dataset of Kenya's terrestrial mammals. We estimated species occurrences per PA by generating distribution extents of every species represented in a PA using QGIS.

After dropping non-terrestrial species whose ranges were represented in coastal areas, we retained 372 species which we further subdivided into three a priori species groups: (i) large carnivores-five Carnivora species weighing $\geq 40 \mathrm{~kg}$ and the African wild dog, (ii) large herbivores -18 species weighing $\geq 100 \mathrm{~kg}$, and (iii) endangered species-38 species under IUCN's threatened categories [near threatened, vulnerable, endangered, and critically endangered] which also overlapped as large carnivores and large herbivores (Online Resource 1: ESM_2). This enabled us to assess how the focal species groups (large carnivores, large herbivores, and the threatened species), which are critical to the utilization of PAs for species conservation, were represented in the current PAs and between designation and governance types.

\section{Phylogenetic tree, functional trait matrix, and estimation of diversity indices}

The molecular phylogeny of Kenya's terrestrial mammals was obtained from the supertree of Kumar et al. (2017), which retained the most species represented in Kenya's PAs after resolving polytomies and singletons (325 species) compared to Upham et al. (2019) (304 species) and Bininda-Emonds et al. (2007) (200 species). The Kumar et al. (2017) database-http://timetree.org/. We extracted the phylogeny of class Mammalia from which we pruned the tree of only species present in Kenya's PAs. As a time-scaled phylogeny from thousands of studies to resolve divergence times (branch lengths) between species and their evolutionary relationships (nodes), the tree was suitable for deriving phylogenetic diversity indices.

For functional traits, we extracted species traits of external body features, diet, and activity patterns that had $>60 \%$ species coverage from Wilman et al. (2014) and Jones et al. (2009). These included adult body mass in grams, integer percentages of 10 diet categories 
(the relative proportion of the species' diet composed of invertebrates, mammals and birds, herptiles, fish, scavenging, vertebrates in general or unknown, fruits, nectar, seeds, and plants), and binary scores of three levels of activity patterns (nocturnal, crepuscular, or diurnal) (Online Resource 1: ESM_2). These traits are essential in mammalian strategies of resource acquisition and usage-place, food, and time: body mass represents anatomical traits while diet and activity represent ecological strategies (Pianka 2011) and are widely used to derive various indices of functional diversity and structure.

Because we aimed to understand how multiple biodiversity dimensions are distributed in PAs and compare between different designation and governance types, we selected, a priori, species richness to represent taxonomic diversity, Faith's phylogenetic diversity index $\left(\mathrm{PD}^{\mathrm{RIC}}\right.$ ) (Faith 1992) to represent phylogenetic richness, and mean pairwise distance (MPD) and mean nearest taxon distance (MNTD) to represent the phylogenetic divergence (Webb et al. 2002; Webb and Donoghue 2005). We further assessed the phylogenetic community structure using the standardized effect sizes of MPD and MNTD—nearest relative index (NRI) and nearest taxon index (NTI), respectively. The functional diversity indices were estimated analogously as those of phylogenetic diversity after translating the traits into a Gower distance matrix. The functional MPD (FD $\left.{ }^{\mathrm{MPD}}\right)$ and MNTD (FD ${ }^{\mathrm{MNTD}}$ ) represented functional divergence (Webb et al. 2002) while the standardized effect size of $\mathrm{FD}^{\mathrm{MPD}}$ and $\mathrm{FD}^{\mathrm{MNTD}}$ (FD ${ }^{\mathrm{NRI}}$ and $\mathrm{FD}^{\mathrm{NTI}}$, respectively) represented functional community structure. Functional richness was represented by Villeger et al. (2008)'s index of functional richness $\left(\mathrm{FD}^{\mathrm{RIC}}\right)$. Additionally, we assessed the wholeness of species representation in various managements and designations relative to the combined species pool using indices of PA-level composition completeness (Pärtel et al. 2013) and uniqueness (Pavoine and Ricotta 2019).

All diversity indices were estimated in R: species richness using vegan (Oksanen et al. 2019), PD ${ }^{\mathrm{RIC}}$, MPD, MNTD, FD ${ }^{\mathrm{MPD}}, \mathrm{FD}^{\mathrm{MNTD}}$, NRI, NTI, FD ${ }^{\mathrm{NRI}}$, and $\mathrm{FD}^{\mathrm{NTI}}$ using picante (Kembel et al. 2010), and FD $^{\mathrm{RIC}}$ using FD (Laliberte and Legendre 2010; Laliberté et al. 2014).

Refer to Online Resource 2: ESM_1 for a more detailed account of the estimation of diversity indices.

\section{Species representation in PAs and identification of priority conservation areas}

The relative proportion of species ranges represented in PAs (area and percentage) was estimated in QGIS separately for all PAs, SPAs, and PPAs (see columns I-N in Online Resource 1: ESM_2). The priority conservation areas for terrestrial mammal conservation were estimated using spatial analysis in Marxan (Ball et al. 2009) for which input files were prepared using the ArcMarxan Toolbox [https://aproposinfosystems.com/en/solutions/arcgis-plugins/ arcmarxan-toolbox/ (Apropos Information Systems Inc. 2021)]. We used Kenya's administrative boundary as planning limits and divided it into 59,971 planning units of $10 \mathrm{~km}^{2}$-hexagons. The planning units intersecting current PAs were assigned status 2 to fix them as 'locked in' reserve systems whose use for conservation is not likely to change, those intersecting within a 5-km radius of a town, municipality, and city centre were assigned status 3 as 'locked out' areas that were not available for inclusion in the reserve system, and the remaining planning units were assigned status 0 as areas 'available' for inclusion in the reserve system. We defined the expected cost of including planning units into conservation areas based on the human footprint index from Venter et al. (2016). The index consolidates several infrastructural facilities and human ecological influences that compete for land use with biodiversity conservation, and 
thus provided a credible baseline cost estimate. For conservation features, we used the 49 species that had been earlier defined as focal species groups (large herbivores, large carnivores, and endangered species). The analysis was implemented using best-fit calibration parameters determined using the ArcMarxan Toolbox: 1000 runs constituting 10 million iterations and a boundary length modifier of 0.001 . We performed two independent analyses, (i) with all PAs fixed as locked in areas and (ii) with just SPAs fixed as locked in areas, to better analyse how the best-solution reserve systems compared between the two scenarios.

\section{Statistical analysis}

The association between diversity indices (as response variables) and PA designation and governance types (as explanatory variables) was explored using univariate analysis of variance and multilevel permutational multivariate analysis of variance, generalized linear mixedeffects model, generalized additive mixed models, and constrained ordination-redundancy analysis. We first estimated the potential confounding of PA size, PA status year, and unequal number of PAs between categories. The influence of differing numbers of PAs in designation and governance categories on diversity comparisons was tested by splitting the full dataset into individual categories and then randomly sampling cases based on the category with the least number of PAs as the baseline in IBM SPSS Statistics v25 using the Random sample of cases function. Category mean indices from the same-group-size dataset were then compared with those of the full dataset. Because the compared means using the full dataset and the randomly sampled dataset remained virtually similar, and the associated statistical significances unchanged (Online Resource 2: ESM_2), consequent comparisons were based on the full dataset using unweighted means with type III sum of squares for analysis of variance (Shaw and Mitchell-Olds 1993). To examine how PA size and status year related to species diversity, we used generalized additive models, with diversity indices as responses and size and status year as predictors, separately. Across species groups, the variance in diversity indices accounted for by PA size and the status year was significant in nearly all indices and varied between species groups (Table 1). Consequently, PA size and status year were included as random effects in the generalized additive mixed models and generalized linear mixed-effects model analyses and as covariables in the redundancy analysis when estimating diversity variances accounted for by the pure influence of PA designation and governance categorizations.

The proportions of diversity variances explained by PA governance and designation categorizations were determined using Bonferroni adjusted R-squared $\left(R_{\text {adj }}^{2}\right)$ and significance level $[p<0.05]$. We also performed pairwise comparisons between PA managements and designations using the multilevel pairwise comparison with permutational multivariate analysis of variance. The analyses were implemented in $\mathrm{R}$ using packages lme4 (Bates et al. 2015) for the generalized linear mixed-effects model, $m g c v$ (Wood 2011) and gamm4 for generalized additive mixed models, vegan (Oksanen et al. 2019) for redundancy analysis, car (Weisberg 2019) for type-III analysis of variance, and pairwiseAdonis (Martinez Arbizu 2020) for multilevel permutational multivariate analysis of variance. 
Table 1 The association of PA size [spatial extend of a protected area (PA)] and status year (year PA was formally recognized as protected) with terrestrial mammal diversity in Kenya

\begin{tabular}{|c|c|c|c|c|c|c|c|}
\hline \multirow{2}{*}{ Species group } & \multirow[t]{2}{*}{ Index } & \multicolumn{3}{|l|}{ PA size } & \multicolumn{3}{|c|}{ PA status year } \\
\hline & & $p$ & $R_{a d j}^{2}$ & $D E x$ & $p$ & $R_{a d j}^{2}$ & $D E x$ \\
\hline \multirow[t]{7}{*}{ Combined species pool } & SR & 0.025 & 0.055 & 0.074 & $<0.001$ & -0.135 & 0.15 \\
\hline & MPD & 0.007 & -0.058 & 0.073 & $<0.001$ & -0.083 & 0.102 \\
\hline & $\mathrm{FD}^{\mathrm{MPD}}$ & $<0.001$ & 0.271 & 0.284 & $<0.001$ & 0.144 & 0.147 \\
\hline & NRI & $<0.001$ & 0.076 & 0.079 & 0.008 & 0.053 & 0.074 \\
\hline & NTI & 0.142 & -0.03 & 0.042 & 0.01 & -0.046 & 0.058 \\
\hline & $\mathrm{FD}^{\mathrm{NRI}}$ & $<0.001$ & -0.224 & 0.234 & $<0.001$ & -0.181 & 0.183 \\
\hline & $\mathrm{FD}^{\mathrm{NTI}}$ & 0.001 & 0.074 & 0.085 & 0.003 & -0.056 & 0.069 \\
\hline \multirow[t]{7}{*}{ Large carnivores } & $\mathrm{SR}$ & $<0.001$ & 0.35 & 0.355 & $<0.001$ & 0.242 & 0.261 \\
\hline & MPD & $<0.001$ & 0.157 & 0.163 & 0.548 & -0.011 & 0.02 \\
\hline & $\mathrm{FD}^{\mathrm{MPD}}$ & 0.018 & 0.033 & -0.039 & $<0.001$ & -0.122 & 0.135 \\
\hline & NRI & 1 & -0.002 & 0.01 & 0.04 & -0.039 & 0.054 \\
\hline & NTI & 1 & -0.003 & 0.011 & 0.025 & 0.044 & 0.057 \\
\hline & $\mathrm{FD}^{\mathrm{NRI}}$ & 1 & -0.004 & 0.001 & 0.001 & 0.066 & 0.078 \\
\hline & $\mathrm{FD}^{\mathrm{NTI}}$ & 1 & -0.005 & 0 & 0.002 & 0.059 & 0.07 \\
\hline \multirow[t]{7}{*}{ Large herbivores } & SR & $<0.001$ & 0.327 & 0.33 & $<0.001$ & 0.16 & 0.18 \\
\hline & MPD & $<0.001$ & 0.15 & 0.161 & $<0.001$ & 0.092 & 0.112 \\
\hline & $\mathrm{FD}^{\mathrm{MPD}}$ & $<0.001$ & 0.087 & 0.091 & $<0.001$ & 0.107 & 0.129 \\
\hline & NRI & $<0.001$ & -0.179 & 0.19 & $<0.001$ & -0.098 & 0.118 \\
\hline & NTI & $<0.001$ & -0.187 & 0.198 & $<0.001$ & -0.112 & 0.132 \\
\hline & $\mathrm{FD}^{\mathrm{NRI}}$ & 1 & -0.003 & 0 & 0.003 & -0.062 & 0.083 \\
\hline & $\mathrm{FD}^{\mathrm{NTI}}$ & 1 & -0.003 & 0.011 & $<0.001$ & -0.12 & 0.142 \\
\hline \multirow[t]{7}{*}{ Endangered species } & $\mathrm{SR}$ & $<0.001$ & 0.453 & 0.459 & $<0.001$ & 0.267 & 0.284 \\
\hline & MPD & 0.067 & 0.032 & 0.042 & 0.004 & 0.054 & 0.067 \\
\hline & $\mathrm{FD}^{\mathrm{MPD}}$ & $<0.001$ & -0.207 & -0.216 & $<0.001$ & -0.092 & 0.101 \\
\hline & NRI & 0.015 & 0.024 & 0.027 & 0.013 & -0.05 & 0.069 \\
\hline & NTI & $<0.001$ & 0.051 & 0.055 & 0.002 & -0.066 & 0.085 \\
\hline & $\mathrm{FD}^{\mathrm{NRI}}$ & $<0.001$ & 0.121 & 0.135 & $<0.001$ & 0.064 & 0.075 \\
\hline & $\mathrm{FD}^{\mathrm{NTI}}$ & $<0.001$ & 0.232 & 0.243 & $<0.001$ & 0.092 & 0.109 \\
\hline
\end{tabular}

The associations were modelled using generalized additive models in $\mathrm{R}$ and included 263 PAs with PA size and 344 with status year reported in World Database on Protected Areas. The coefficients of associations are represented by significant values, $p<0.05$, indicated in bold. The rationale for defining the species groups (large carnivores, large herbivores, and endangered species) is explained in the main text

$p=$ p-value, $R_{a d j}^{2}=$ adjusted $\mathrm{r}$ squared, $D E x=$ percentage proportion of deviance in diversity index explained by the effects (PA size and PA status year)

\section{Results}

\section{The representation of Kenya's terrestrial mammals in protected areas}

We retained 365 species of the initial 372 species, whose distributions overlapped with at least one PA (Online Resource 1: ESM_2). The 365 species comprised 14 orders, of which Chiroptera and Rodentia comprised more than half (57\%). The remaining $43 \%$ consisted 
of eight orders each constituting $<1 \%$ of all species ( $<10$ species) —Proboscidea, Tubulidentata, Afrosoricida, Lagomorpha, Pholidota, Hyracoidea, Perissodactyla, and Macroscelidea and four orders each constituting 5-11\%_Primates, Carnivora, Eulipotyphla, and Cetartiodactyla (Online Resource 1: ESM_2). Most of the species represented in PAs were small mammals $(\leq 10 \mathrm{~kg})-305$ species $(84 \%)$, with medium-sized species $(10-50 \mathrm{~kg})$ comprising $8 \%$ (28 species), medium-big sized (50-100 kg) comprising 3\% (12 species), and big-sized ( $\geq 100 \mathrm{~kg}$ ) comprising $5 \%$ (20 species). Based on the ranking of species risk of extinction by IUCN, most of the PA-represented species were of low conservation concern ( $82 \%$ least concern and $7 \%$ data deficient) with the remaining $11 \%$ being vulnerable (4\%), near threatened (4\%), endangered (2\%), and critically endangered (1\%) (Online Resource 1: ESM_2). Over 90\% of the PA-represented species occurred in SPAs excluding forest reserves (i.e., strict SPAs), which was higher than those in PAs under IUCN management categories II, IV, and VI $(84.7 \%, 67.1 \%$, and 79.9\%, respectively) (Table 2, Online Resource 2: ESM_3). The PPAs contained virtually the same count of unique species as the strict SPAs (89.9\% and 90.7\%, respectively) (Table 2, Online Resource 2: ESM_3). There were more species represented in $<50 \%$ of PAs (225 species), and only $17 \%$ were represented in $>90 \%$ of PAs, with the remaining $21 \%$ represented in $50-90 \%$ of PAs (Online Resource 2: ESM_4). The proportion of species' ranges overlapping PAs varied between $22.9 \%$ in all PAs, $12.3 \%$ in SPAs, and 4.3\% in PPAs (Online Resource 2: ESM_4).

There was no systematic geographical pattern in species composition between PAs according to management and designation types (Fig. 1). However, species richness and indices highly correlated with it $\left[\mathrm{PD}^{\mathrm{RIC}}, \mathrm{MNTD}, \mathrm{FD}^{\mathrm{MNTD}}\right.$, and $\mathrm{FD}^{\mathrm{RIC}}$ (see the bivariate correlations between indices in Online Resource 2: ESM_5)] depicted geographical trends. For instance, species richness was higher towards the southwestern half of Kenya and lower towards the northeastern half while the community structure indices (NRI, NTI, FD ${ }^{\mathrm{NRI}}$, and $\mathrm{FD}^{\mathrm{NTI}}$ ) did not portray evident geographical trends (Online Resource 2: ESM_6).

The analysis of spatial conservation prioritization showed that at a $1 / 3$ range coverage target, the 49 focal species would be adequately represented in priority conservation areas, in both cases when all PAs or just SPAs were locked in (Online Resource 2: ESM_7). The best solution when all PAs were locked in included 17,936 planning units in priority conservation areas, of which existing PAs overlapped with 11,437 planning units $(63.8 \%$ coverage) and 14,253 planning units (79.5\% coverage) had $>90 \%$ selection frequency. When only SPAs were locked in, 18,326 planning units were included in the best-solution reserve system, of which existing SPAs overlapped with 5390 planning units (29.4\% coverage) and 12,982 planning units (70.8\% coverage) had $>90 \%$ selection frequency. Therefore, when considering all current PAs as locked in, achieving a 1/3 range representation target for focal species in priority conservation areas require an additional $36.2 \%$ of their size to be added to the reserve system, while when considering only SPAs as protected, $70.6 \%$ of their size should be added to priority conservation areas to achieve the $1 / 3$ range target. The selection frequency of the best-solution planning units showed that the additional priority/irreplaceable conservation areas ( $>90 \%$ selection frequency) were always located around existing PAs, with few exceptions (Fig. 2).

\section{Variation of diversity metrics between PA management and designation categories}

The redundancy analysis showed that species composition differences explained by PA designation and governance types after controlling for PA size and the status year was low, with $R_{\text {adj }}^{2}$ ranging from 0.07 to 0.13 despite being statistically significant-combined 


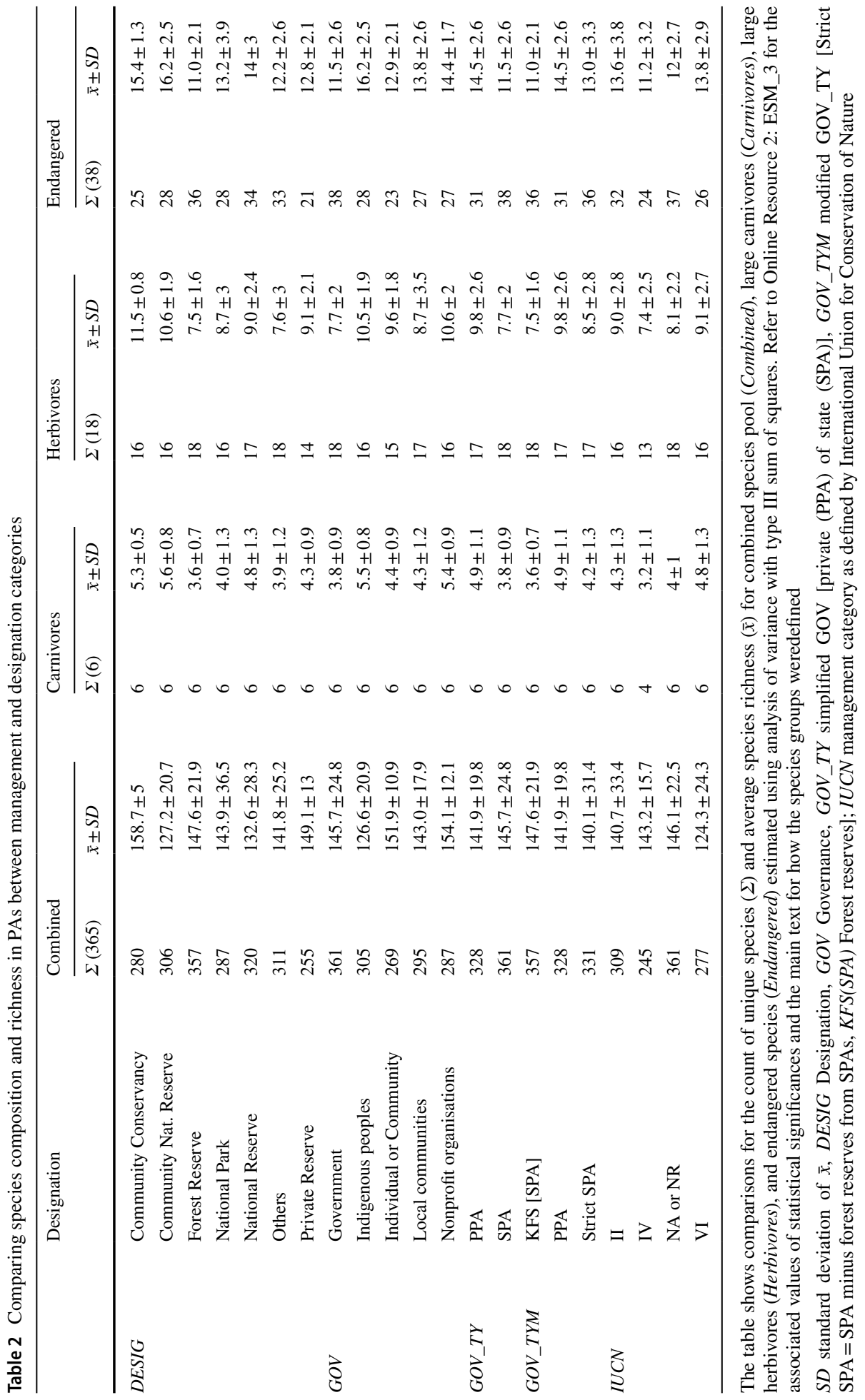



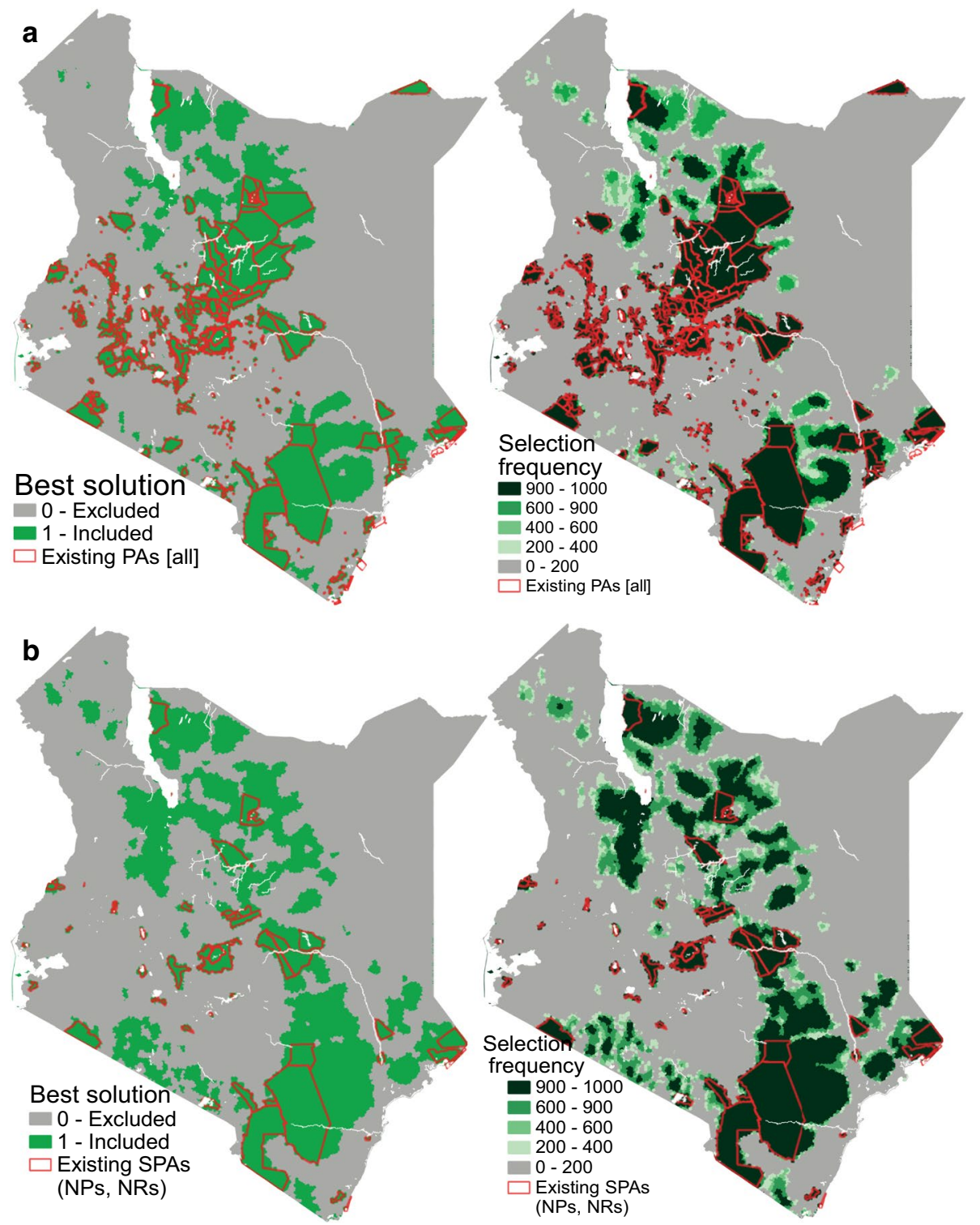

Fig. 2 The priority conservation areas in Kenya based on focal species (large carnivores, large herbivores, and endangered species) ranges. The figures illustrate the best solution reserve areas for achieving a $1 / 3$ range representation when all protected areas are locked in (a) and when only government-protected areas (National parks [NPs] and National reserves [NRs]) are locked in (b). The left maps show the binary inclusion-exclusion of planning units in the best solution while the right maps show the selection frequency of the planning units' inclusion in the best solution

species $\left(F 3.9, R_{\text {adj }}^{2} 0.1, p 0.001\right)$, large carnivores $\left(F 5.9, R_{\text {adj }}^{2} 0.13, p 0.001\right)$, large herbivores $\left(F 3.2, R_{\text {adj }}^{2} 0.07, p 0.001\right)$, endangered species $\left(F 3.6, R_{\text {adj }}^{2} 0.08, p 0.001\right)$. Based on the combined species pool, species richness declined significantly with PA status year in national parks, forest reserves, and community nature reserves but increased 
non-significantly in community conservancies, national reserves, and private reserves (Fig. 3). Against PA size, species richness increased in national parks, forest reserves, and community conservancies but decreased in national reserves and community nature reserves with increasing size; all associations being significant except in national parks (Fig. 3).

Low diversity variances were accounted for by differences in PA management and designations types, with associations nonsignificant for all diversity indices except species richness and MPD (Online Resource 2: ESM_9). The total unique species was higher in SPAs (national reserves, forest reserves) than in PPAs (community nature reserves, private reserves, and community conservancies) (Table 2, Online Resource 2: ESM_3). Average species richness per PA significantly differed between designation types and was highest in community conservancies, followed by private reserves, forest reserves, national parks, national reserves, and lowest in community nature reserves (Table 2, Online Resource 2: ESM_3). Similarly, the richness indices $\left(\mathrm{PD}^{\mathrm{RIC}}\right.$ and $\mathrm{FD}^{\mathrm{RIC}}$ ) and divergence indices (MPD, MNTD, FD ${ }^{\mathrm{MPD}}$, and $\mathrm{FD}^{\mathrm{MNTD}}$ ) differed significantly between designation and governance types, and were always higher in PPA designations (community conservancies and community nature reserves) compared to SPA designations (national parks and national reserves) (Online Resource 3). The community structure indices showed more PAs were clustered for NRI, FD ${ }^{\mathrm{NRI}}$, and $\mathrm{FD}^{\mathrm{NTI}}$ but not NTI, with the distribution of clustered or overdispersed PAs not systematic to particular designation or governance types (Online Resource 2: ESM_10). Species composition dissimilarity/turnover, phylogenetic and functional uniqueness, and composition completeness significantly differed between designation and governance types. There was a lower turnover in PPAs (community conservancies, community nature reserves, and private reserves) compared to the SPAs (national parks and national reserves) but comparable uniqueness and completeness between the designations (Fig. 4). Multilevel permutational multivariate analysis of variance based on all diversity indices showed random pairwise differences between designation and governance types, with more nonsignificant differences than significant ones (Online Resource 2: ESM_11).
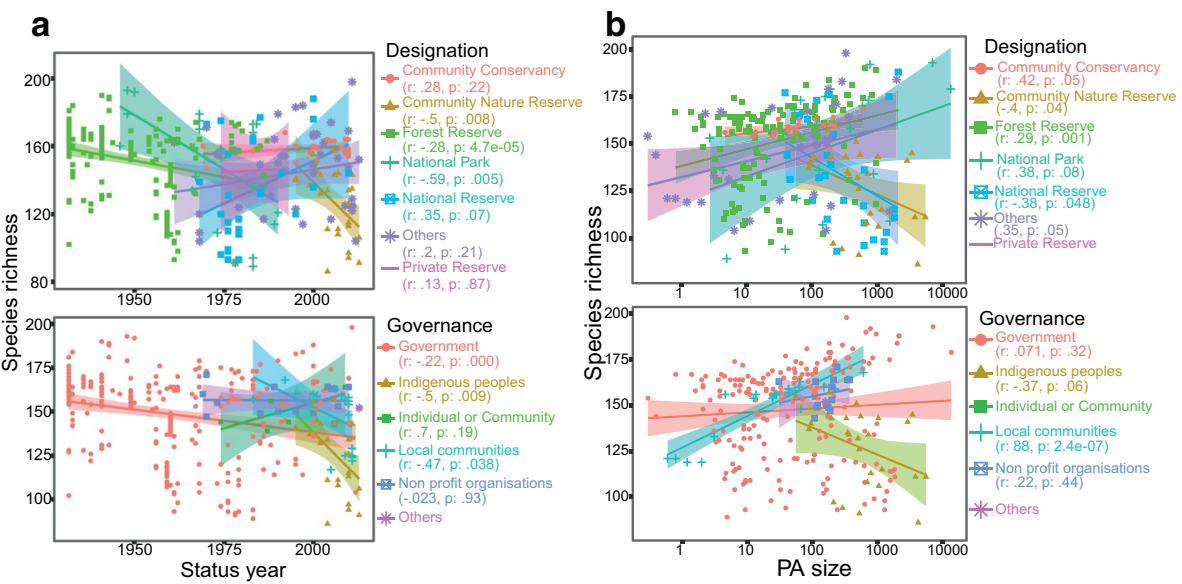

Fig. 3 Variance of species richness with protected areas status year (a) and spatial size (b). The plots are portioned by management and governance categorizations using different shapes and colour and corresponding linear regression scores for the association of species richness with year and size are shown for the different categories 


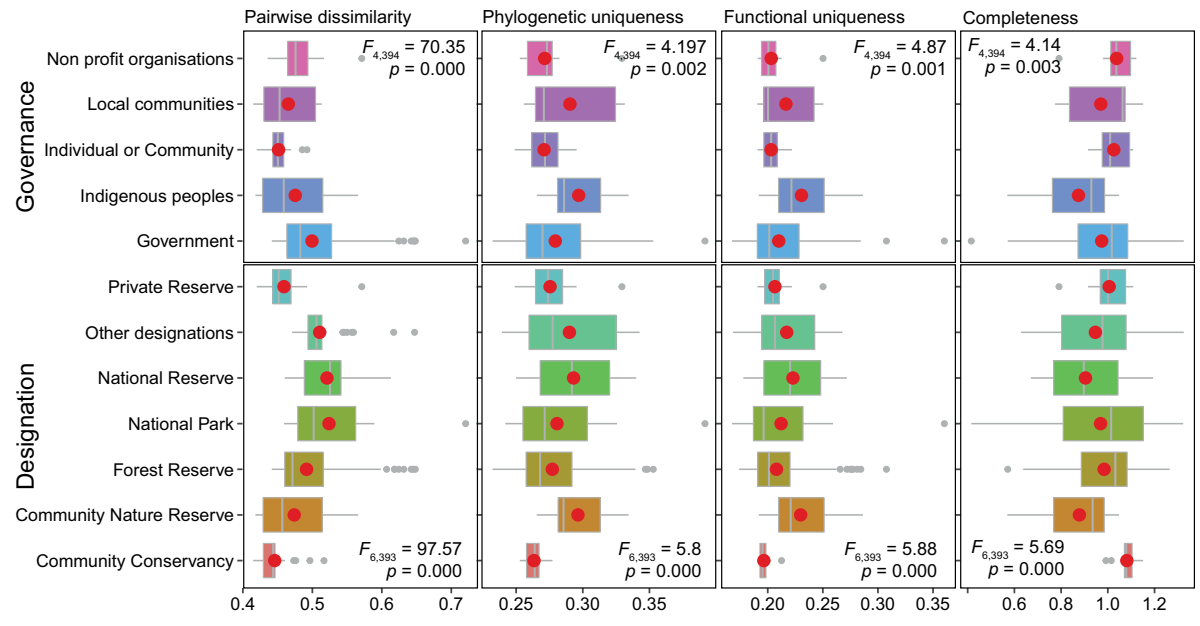

Fig. 4 The variance of species turnover [Pairwise dissimilarity], uniqueness, and completeness of terrestrial mammals in protected areas in Kenya between management (Governance) and designation (Designation) categories. The red dots show the mean values per category while the grey line dividing boxes are the median values

\section{Distribution of focal species-large carnivores and large herbivores and endangered species}

The total unique species in the focal species groups (large herbivores, endangered species, and large carnivores) were higher in SPAs than in PPAs, in contrast to average species richness which was higher in PPAs than in SPAs (Table 2, Online Resource 2: ESM_3). All six large carnivore species were represented in every designation type, while only forest reserves contained all 18 species of large herbivores followed by national reserves (17 species) with the remaining designation types missing between two and four species (Table 2). For endangered species, none of the designation categories contained all 38 species. Forest reserves had the highest representation (36 species) followed by national reserves (34 species), while private reserves and community conservancies had the lowest representation (21 and 25 species, respectively). Like in the combined species pool, averaged species richness significantly differed between categories and was always higher in designations under PPAs (Table 2, Online Resource 2: ESM_3). The phylogenetic structure indices (NRI and NTI) and functional structure $\left(\mathrm{FD}^{\mathrm{NRI}}\right.$ and $\mathrm{FD}^{\mathrm{NTI}}$ ) were not systematically patterned by management and designation types (Fig. 5, Online Resource 2: ESM_10). More PAs were clustered for all structure indices in large carnivores and large herbivores except $\mathrm{FD}^{\mathrm{NTI}}$ of the latter while all PAs were overdispersed for endangered species except NRI (Online Resource 2: ESM_10).

The association of diversity variances and PA size and status year between species groups corresponded with the combined species pool-increasing with PA size but declining with status year, with variable statistical support and a few deviances (Fig. 3). For instance, large herbivores and endangered species richness declined with increasing PA size in community conservancies but increased in all other designation types while large carnivores increased in all designations except in community nature reserves (Online Resource 2: ESM_8). 


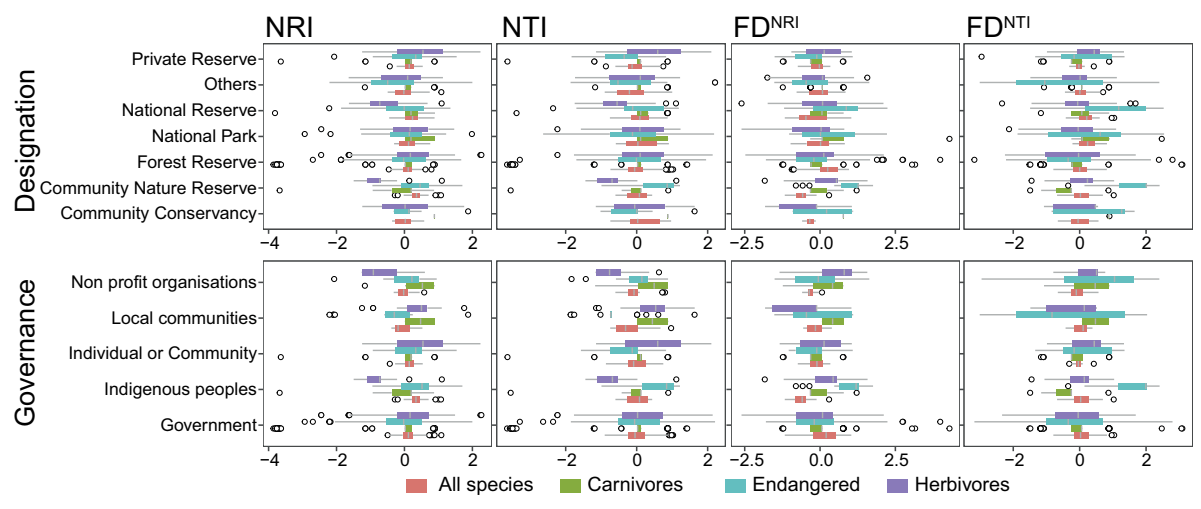

Fig. 5 Comparison of the community structure of terrestrial mammals in protected areas in Kenya based on phylogenetic and functional diversity. Boxplots show how phylogenetic structure (NRI and NTI) and functional structure $\left(\mathrm{FD}^{\mathrm{NRI}}\right.$ and $\mathrm{FD}^{\mathrm{NTI}}$ ) compare between management (Governance) and designation (Designation) types. Median values per category are represented by line dividing boxes. See Online Resource 2: ESM_10 for the distribution of these indices in individual protected areas and Online Resource 3 for associated significance test values

\section{Discussion}

We investigated how ranges of terrestrial mammals are represented in PAs in Kenya, whether PA management and designation types influence diversity distribution patterns, and how state-managed PAs compare with privately-managed ones in the species representation. Our results showed nearly all terrestrial mammals in Kenya represented in PAs. However, the relative proportion of the ranges overlapping PAs was low, in agreement with the spatial conservation prioritization analysis which showed significant expansion of current PAs was needed to achieve a one-third coverage of species ranges in the best-solution conservation areas. Differences in PA governance and designation types were not systematically nor significantly associated with diversity distribution trends, and while there were more unique species in SPAs than in PPAs, averaged diversity indices were comparable between categories. Following, we discuss these findings in detail.

To answer how ranges and diversity of terrestrial mammals in Kenya are represented in PAs, we found nearly all terrestrial mammals in Kenya were represented (ca. 98\%) albeit the relative proportions of the 'protected ranges' were low. While this compares with studies such as Gonzalez-Maya et al. (2015) where nearly all of Costa Rica's mammals were represented in PAs, it illustrates that evaluating species conservation status based on range overlap in PAs might overestimate their overall range protection statuses. Similarly, Tyrrell et al. (2020) found relatively lower proportions of Kenya's terrestrial mammals were adequately conserved in PAs and Coad et al. (2019) found low range proportions of terrestrial mammals were sufficiently represented within PAs globally. The relative range proportions overlapping PAs declined further when considering only strict PAs as adequately protected (i.e., national parks and national reserves), which was also supported by the spatial conservation prioritization analysis that showed considerable expansion of conservation areas beyond the existing PAs needed to achieve a one-third range representation of focal species. De Alban et al. (2021) also found that expanding conservation areas beyond existing PAs in Myanmar was needed to achieve a $30 \%$ representation target of species ranges and habitats. Notably, however, the high 
number of species with ranges represented in PAs and the clumping of irreplaceable priority conservation areas around existing PAs (Fig. 2) presents an ideal conservation opportunity and backdrop for the use of PAs to protect species and habitats/ecoregions. Because there are currently no alternative wildlife conservation tools besides PAs, they are indispensable in Kenya's wildlife conservation pursuits, offering species with refugial ecosystems (Joppa et al. 2016) and serving as stronghold of threatened species (Pacifici et al. 2020). Also, PAs represent the most practical approach to effectively control land-use competition for biodiversity conservation with humans (settlement and agriculture), which is particularly severe in tropical Africa (Food and Agriculture Organization 2020). The observed decreasing species richness with status year likely reflects deteriorating species diversity, population, and ecological conditions in Kenya's PAs over time, in the process, driving wildlife onto unprotected human-dominated areas. While we did not target untangling the specific non-management and non-designation factors driving the observed diversity trends, the pattern of biogeographical regionalization and diversity distributions in PAs (Online Resource 2: ESM_6) correspond to Kenya's eco-climatic zonation as patterned by topography, water bodies, precipitation, temperature, and evapotranspiration regimes (Western et al. 2015). This suggests that abiotic variables such as climate and geography might be stronger predictors of the diversity variances, as is common among African mammals (Kamilar 2009; Kamilar et al. 2015; Rowan et al. 2016) and mammal diversity patterns in the tropics (Stevens et al. 2003; Rapacciuolo et al. 2019).

We also asked whether PA management and designation categorizations influence the diversity and community structure of terrestrial mammals. Our results showed PA designation and governance differences accounted for very low proportions of diversity variances and were not systematically associated with diversity and distribution trends. This agrees with previous studies (Stolton et al. 2017; Maxwell et al. 2020) and suggests that governmental and non-governmental stakeholders in PA biodiversity conservation in Kenya have equal contributions and should collaborate closely to improve the efficiency of PAs as wildlife conservation tools. The stricter management approaches (as practised in National Parks and National Reserves) appear to not translate to better ecological conditions and higher species richness in individual PAs, in contrast with expectations (Riggio et al. 2019; Ayivor et al. 2020). Unlike the averaged indices, the higher count of unique species in SPAs compared to PPAs can be explained by the temporal trend of PA designations, where SPAs are dominantly older. In these older PAs, species have had adequate time to naturally assort into available niches and stabilize/adapt ecological functions, leading to richer and diverse assemblages. The distribution and assembling patterns of the uncharismatic smallsized that comprise a dominant majority of Kenya's mammals should be ecologically more stable because they hardly influence biodiversity conservation pursuit in PAs (Asaad et al. 2017). As such, their higher diversity in older and larger compared to younger and smaller PAs plausibly reflect actual ecological interactions (Brashares et al. 2001). For this, the observed decrease in species richness with PA status year reflects deteriorations of PA ecological conditions over time, which might also explain the increase of wildlife populations occurring outside PAs (Ogutu et al. 2016) and the decline of wildlife populations inside PAs (Craigie et al. 2010). Overall, the differences in diversity variations between government versus private managements concur with Ferraro et al. (2013) where strict PA management was not better at delivering conservation objectives across several tropical countries (Bolivia, Costa Rica, Indonesia, and Thailand) but contrasts Riggio et al. (2019) and Oberosler et al. (2020) where stricter PA management enhanced the welfare of ecosystems and species ecology in Eastern Africa. Nation-wide PA level assessment of management 
effectiveness in Kenya is needed to resolve, with greater certainty, how designation and governance differences impact biodiversity conservation outcomes and species community ecology.

Thirdly, we asked how SPAs compare with PPAs in the representation of Kenya's mammals, especially the focal species-large carnivores, large herbivores, and endangered species. We found more unique focal species represented in SPAs (national parks, national reserves, and forest reserves) compared to the PPAs, which is unsurprising because they are accorded greater conservation concern and are almost exclusively found in government-managed PAs (Craigie et al. 2010; Bowyer et al. 2019), with their populations actively monitored and occasionally manipulated, through, for instance, translocations. Also, several SPAs are biogeographically unique ecosystems for globally endangered and range-restricted mammals, such as the Mountain Bongo in Mt. Kenya and Aberdares, the Hirola in the Northern Rangeland Trust Coast PAs, the Sitatunga in the Lake Victoria Basin PAs, and the Giant ground pangolin whose extreme eastern distribution is represented in some of the Lake Victoria Basin PAs. The SPAs also have more extensive nationwide distribution compared to PPAs, with PAs such as the Malka Mari and Lake Turkana national parks which are located in very remote areas serving as critical protective islands and likely to host highly phylogenetically and functionally diverse mammal assemblages. Even so, several PPAs are exceptionally vital to regional conservation of Kenya's threatened mammals, such as the Lewa and Ol Pejeta Conservancies (black rhinos, elephants, and Grevy's zebra). Joint efforts between PPAs and SPAs, such as in the Tsavo Conservation Area, the Northern Rangelands Trust, and Mara North Conservancy are the lifeline of wildlife migratory routes and crucial buffers to human-wildlife conflicts, thus, critical for the persistence of the larger and threatened species (Munoz Brenes et al. 2018; Ferreira et al. 2020; Oberosler et al. 2020; Pacifici et al. 2020). Despite the shortfall in national coverage and connectivity between PAs, the current PA network has the potential to successfully guarantee effective conservation of mammal ranges since wildlife populations within protected ecosystems persist substantially stabler than in unprotected areas, even under changing climates and intensifying human disturbance (Hansen and DeFries 2007; Thomas and Gillingham 2015; Boakes et al. 2019). However, such success depends on extending conservation strategies beyond PAs onto unprotected areas and entrenching these approaches into national wildlife policy legislations for long-term sustainability (Tack et al. 2019; Tyrrell et al. 2020). To this end, the greatest challenge is the integration of communities adjacent to wildlife areas within ecologically sound and socially embraced management plans. As the Protected Planet Report 2020 (UNEP-WCMC and IUCN 2021b) highlighted, successful engagement of communities, individuals, and private organizations by committed governments was vital towards attaining a 17\% global PA coverage. These government-private-community feedback frameworks of PAs-wildlife management constitute the backdrop of successful conservation target-setting beyond the Aichi Biodiversity Targets and should be embraced in Kenya. Conventionally, because SPAs have more explicit definitions, management regimes, and funding surety, regardless of their economic profitability, they are currently a more enduring model of biodiversity conservation (Riggio et al. 2019). However, increasingly declining conservation funding opportunities for both PPAs and SPAs continue to aggravate the management of PA challenges such as humanwildlife conflicts, illegal bushmeat hunting, and illegal logging, and keeping private interest in wildlife conservation (Lindsey et al. 2020; McElwee et al. 2020). This has forced wildlife and conservation stakeholders to embrace utilitarian initiatives that better sustain PAs' flow of ecological benefits to humans and sustain their interests to protect natural resources (Guerry et al. 2015). Of the two primary sources of benefits and incentives for 
conservation in Africa-tourism and trophy hunting - the latter has remained controversial and an unpopular conservation funding source except for southern Africa (Lindsey et al. 2007), although the evidence suggests it is an important conservation tool when sustainably implemented (Lindsey et al. 2006; Dickman et al. 2019). Studies also show that the classical conservation approach of relying on touristic incomes and government support cannot sustain biodiversity conservation for many biodiversity-rich countries (Bang and Khadakkar 2020; Hockings et al. 2020; Lindsey et al. 2020; McElwee et al. 2020). While Kenya banned trophy hunting in 1977 aiming to curb poaching, its progress in wildlife conservation since then has been an underperformance compared to countries that integrated sustainable trophy hunting into conservational frameworks, such as Neighbouring Tanzania and the southern African countries-South Africa, Zimbabwe, and Botswana (Lindsey et al. 2006; Ogutu et al. 2016). Sustainable trophy hunting can also lead to improved food resources, increased litter size and survival through the density-dependent reproduction/ survival responses (Bowyer et al. 2019).

The geographical trends in diversity distributions bear on the performance of PAs for wildlife protection. For one, the central, western, and southwestern Kenya PAs which had the highest taxonomic, phylogenetic, and functional richness of terrestrial mammals are also surrounded by populous and intensively farmed buffer zones (Republic of Kenya 2015), implying that curbing human encroachment onto wildlife areas can be challenging. The human constraints on PA peripheries commonly drive wildlife emigration from PAs onto the settlement and farmed areas (Hansen and DeFries 2007; Hansen et al. 2011; Veldhuis et al. 2019), resulting in cyclic human-wildlife conflicts (Ogutu et al. 2016; Ojwang' et al. 2017; Mukeka et al. 2019), which is an indication of ineffective PA biodiversity conservation performance. The suitability of these regions as priority conservation areas was downplayed by the Marxan analysis which, despite the high mammal diversities, mostly excluded them from the best solution reserve systems (Fig. 2). In these areas, PA managements should exploit existing provisions for maintaining interconnectivity (Watts et al. 2017; Saura et al. 2019) by building on the findings of studies such as Ojwang' et al. (2017) where key wildlife migration corridors were observed to connect PA networks with nonprotected ecosystems based on temporal variability in habitat suitability. Sustaining the connectivity of PA and non-PA lands based on wildlife habitat use can also benefit from nationally harmonized land ownership legislation that incentivizes increased private participation (Saura et al. 2018, 2019), as a more integrative, effective, and equitable conservation approach (Muchapondwa and Stage 2015; Tack et al. 2019). The species whose ranges did not overlap any PA had distributions that spanned the extremes of Kenya's national boundary, with primary ranges in neighbouring countries (Tanzania, Uganda, South Sudan, Ethiopia, and Somalia). Their representation in PA systems can be attained through transboundary collaborations in PA design and management and national responsibility species initiatives towards maximizing ecological connectivity and representativeness (area-based conservation measures). Such transboundary conservation initiatives are increasingly recognized as critical components of biodiversity conservation in PAs (Schmeller et al. 2014; Venter et al. 2014; Kark et al. 2015; Saura et al. 2018; Kukkala et al. 2019; Maxwell et al. 2020) but are currently hardly adopted in East Africa. While we used the representation of species ranges in PAs, the approach can be prone to misestimations of PA and range coverages. Therefore, our results should be interpreted with the necessary caution. Kenya currently lacks nationwide standardized information on the protected biodiversity in PAs, even for the charismatic large mammals; for this, managements should direct more concerted efforts towards PA-level biodiversity inventories that can inform better-targeted conservation interventions and, thus, better outcomes. 


\section{Conclusion}

Protected areas are vital biodiversity conservation tools despite debates concerning their effectiveness in combating species declines and ecosystem degradations. And as the 2020 Protected Planet Report (UNEP-WCMC and IUCN 2021b) underscored, biodiversity conservation success beyond Aichi Biodiversity Target 11 can only be achieved through effective PA management and just governance. Here, our analysis of the effectiveness of PA management in Kenya based on how differences in governance and designation types associate with terrestrial mammal ranges and diversity distributions provides some novel insights. While nearly all the terrestrial mammals in Kenya were represented in at least a PA, the relative proportions of the represented ranges were low, such that achieving a one third range coverage of focal species' ranges in a best-solution reserve system, for instance, needed substantial expansion of conservation areas beyond current PA extents. Differences in governance and designation were not systematically associated with diversity variances, and while there were more unique species in state-managed PAs compared to privatelymanaged PAs, averaged diversity coefficients were comparable. These findings illustrate that, in Kenya, and as applicable across other countries, governmental and non-governmental stakeholders contribute similarly to wildlife conservation in PAs. The persistence of terrestrial mammals in PAs, therefore, depends upon clearly defined collaboration schemes between SPAs and PPAs managements in the appraisal of conservation performance and challenges. This would ensure that all PAs sustainably persist as protective ecosystems for mammals through, for instance, buffering PPAs of operational crises arising from unprecedented challenges to their profit-based conservation approaches (Bang and Khadakkar 2020; Lindsey et al. 2020; McElwee et al. 2020). Such collaboration also aligns with the trend of shifting wildlife conservation in Africa from classical exclusive state-management regimes to broader governances where several stakeholders are involved in the planning and execution of policies (Muchapondwa and Stage 2015).

Supplementary Information The online version contains supplementary material available at https://doi. org/10.1007/s10531-021-02276-7.

Acknowledgements We are grateful to three reviewers and one senior editor whose generous comments and suggestions added much quality to the manuscript. The mammal survey fieldworks in Kenya associated with the work were permitted by the Kenya Wildlife Service and Kenya Forest Service whose rangers also provided security and logistical support in the field. We also thank the personnel at the Zoology Department and Mammalogy Section of the National Museums of Kenya for facilitating operations during the field surveys.

Funding (i) CAS-TWAS President's Fellowship Program, (ii) Sino-Africa Joint Research Centre, Chinese Academy of Sciences [SAJC201612].

Data availability The raw datasets used in the study are available from free public datasets. The species range and occurrence data are available from the International Union for Conservation of Nature [https:// www.iucnredlist.org/resources/spatial-data-download] and Global Biodiversity Information Facility [https:// doi.org/10.15468/dl.y8a58w]. The phylogenetic tree is available from TimeTree [http://timetree.org/] and functional traits are available from EltonTraits [http://www.esapubs.org/archive/ecol/E095/178/\#data] and PanTHERIA [http://esapubs.org/archive/ecol/E090/184/\#data]. Other data not included in the published article and its supplementary material files can be obtained from the corresponding author on request.

\section{Declarations}

Conflict of interest The authors declare that they have no known competing financial interests or personal relationships that could have influenced the work reported in this paper. 
Open Access This article is licensed under a Creative Commons Attribution 4.0 International License, which permits use, sharing, adaptation, distribution and reproduction in any medium or format, as long as you give appropriate credit to the original author(s) and the source, provide a link to the Creative Commons licence, and indicate if changes were made. The images or other third party material in this article are included in the article's Creative Commons licence, unless indicated otherwise in a credit line to the material. If material is not included in the article's Creative Commons licence and your intended use is not permitted by statutory regulation or exceeds the permitted use, you will need to obtain permission directly from the copyright holder. To view a copy of this licence, visit http://creativecommons.org/licenses/by/4.0/.

\section{References}

Apropos Information Systems Inc (2021) ArcMarxan toolbox, Version 2.0.2. https://aproposinfosystems. com/en/solutions/arcgis-plugins/arcmarxan-toolbox/. Accessed 23 June 2021

Asaad I, Lundquist CJ, Erdmann MV, Costello MJ (2017) Ecological criteria to identify areas for biodiversity conservation. Biol Cons 213:309-316. https://doi.org/10.1016/j.biocon.2016.10.007

Ayivor JS, Gordon C, Tobin GA, Ntiamoa-Baidu Y (2020) Evaluation of management effectiveness of protected areas in the Volta Basin, Ghana: perspectives on the methodology for evaluation, protected area financing and community participation. J Environ Planning Policy Manage 22:239255. https://doi.org/10.1080/1523908X.2019.1705153

Ball IR, Possingham HP, Watts ME (2009) Marxan and relatives: Software for spatial conservation prioritization. In: Moilanen A, Wilson KA, Possingham HP (eds) Spatial conservation prioritisation: quantitative methods and computational tools. Oxford University Press, Oxford, pp 185-210

Balmford A, Green JMH, Anderson M, Beresford J, Huang C, Naidoo R et al (2015) Walk on the wild side: estimating the global magnitude of visits to protected areas. PLoS Biol 13:e1002074. https:// doi.org/10.1371/journal.pbio.1002074

Bang A, Khadakkar S (2020) Opinion: Biodiversity conservation during a global crisis: consequences and the way forward. Proc Natl Acad Sci 117:29995. https://doi.org/10.1073/pnas.2021460117

Barnes M (2015) Aichi targets: protect biodiversity, not just area. Nature 526:195. https://doi.org/10. $1038 / 526195 \mathrm{e}$

Bates D, Mächler M, Bolker B, Walker S (2015) fitting linear mixed-effects models using lme4. J Stat Softw. https://doi.org/10.18637/jss.v067.i01

Bininda-Emonds OR, Cardillo M, Jones KE, MacPhee RD, Beck RM, Grenyer R et al (2007) The delayed rise of present-day mammals. Nature 446:507-512. https://doi.org/10.1038/nature05634

Boakes EH, Fuller RA, McGowan PJK (2019) The extirpation of species outside protected areas. Conserv Lett 12:e12608. https://doi.org/10.1111/conl.12608

Bogoni JA, Pires JSR, Graipel ME, Peroni N, Peres CA (2018) Wish you were here: how defaunated is the Atlantic Forest biome of its medium- to large-bodied mammal fauna? PLoS ONE 13:e0204515. https://doi.org/10.1371/journal.pone.0204515

Bowyer RT, Boyce MS, Goheen JR, Rachlow JL (2019) Conservation of the world's mammals: status, protected areas, community efforts, and hunting. J Mammal 100:923-941. https://doi.org/10.1093/ jmammal/gyy 180

Brashares JS, Arcese P, Sam MK (2001) Human demography and reserve size predict wildlife extinction in West Africa. Proc R Soc Lond B 268:2473-2478. https://doi.org/10.1098/rspb.2001.1815

Cadotte MW, Tucker CM (2018) Difficult decisions: strategies for conservation prioritization when taxonomic, phylogenetic and functional diversity are not spatially congruent. Biol Conserv 225:128133. https://doi.org/10.1016/j.biocon.2018.06.014

Caro T (2010) Conservation by proxy: indicator, umbrella, keystone, flagship, and other surrogate species. Island Press, Washington, DC

Carter E, Adams WM, Hutton J (2008) Private protected areas: management regimes, tenure arrangements and protected area categorization in East Africa. Oryx 42:177-186. https://doi.org/10.1017/ s0030605308007655

Ceballos G, Ehrlich PR, Barnosky AD, Garcia A, Pringle RM, Palmer TM (2015) Accelerated modern human-induced species losses: entering the sixth mass extinction. Sci Adv 1:e1400253. https:// doi.org/10.1126/sciadv.1400253

Chao A, Chiu C-H, Jost L (2014) Unifying species diversity, phylogenetic diversity, functional diversity, and related similarity and differentiation measures through hill numbers. Annu Rev Ecol Evol Syst 45:297-324. https://doi.org/10.1146/annurev-ecolsys-120213-091540 
Chape S, Harrison J, Spalding M, Lysenko I (2005) Measuring the extent and effectiveness of protected areas as an indicator for meeting global biodiversity targets. Philos Trans R Soc Lond B Biol Sci 360:443-455. https://doi.org/10.1098/rstb.2004.1592

Coad L, Leverington F, Knights K, Geldmann J, Eassom A, Kapos V et al (2015) Measuring impact of protected area management interventions: current and future use of the global database of protected area management effectiveness. Philos Trans R Soc B 370:20140281. https://doi.org/10. 1098/rstb.2014.0281

Coad L, Watson JE, Geldmann J, Burgess ND, Leverington F, Hockings M et al (2019) Widespread shortfalls in protected area resourcing undermine efforts to conserve biodiversity. Front Ecol Environ 17:259-264. https://doi.org/10.1002/fee.2042

Craigie ID, Baillie JEM, Balmford A, Carbone C, Collen B, Green RE, Hutton JM (2010) Large mammal population declines in Africa's protected areas. Biol Conserv 143:2221-2228. https://doi.org/10. 1016/j.biocon.2010.06.007

De Alban JDT, Leong BPI, Venegas-Li R, Connette GM, Jamaludin J, Latt KT et al (2021) Conservation beyond the existing protected area network is required to improve species and habitat representation in a global biodiversity hotspot. Biol Conserv 257:109105. https://doi.org/10.1016/j.biocon.2021. 109105

Devictor V, Mouillot D, Meynard C, Jiguet F, Thuiller W, Mouquet N (2010) Spatial mismatch and congruence between taxonomic, phylogenetic and functional diversity: the need for integrative conservation strategies in a changing world. Ecol Lett 13:1030-1040. https://doi.org/10.1111/j.1461-0248.2010. 01493.x

Dickman A, Cooney R, Johnson PJ, Louis MP, Roe D (2019) Trophy hunting bans imperil biodiversity. Science 365:874. https://doi.org/10.1126/science.aaz0735

Duffy JE (2002) Biodiversity and ecosystem function: the consumer connection. Oikos 99:201-219. https:// doi.org/10.1034/j.1600-0706.2002.990201.x

Edie SM, Jablonski D, Valentine JW (2018) Contrasting responses of functional diversity to major losses in taxonomic diversity. Proc Natl Acad Sci U S A 115:732-737. https://doi.org/10.1073/pnas.17176 36115

Ervin J (2003) Rapid assessment of protected area management effectiveness in four countries. Bioscience 53:833-841. https://doi.org/10.1641/0006-3568(2003)053[0833:Raopam]2.0.Co;2

Faith DP (1992) Conservation evaluation and phylogenetic diversity. Biol Conserv 61:1-10. https://doi.org/ 10.1016/0006-3207(92)91201-3

Faith DP (2016) The PD phylogenetic diversity framework: linking evolutionary history to feature diversity for biodiversity conservation. In: Pellens R, Grandcolas P (eds) Biodiversity conservation and phylogenetic systematics. Topics in biodiversity and conservation, vol 14. Springer International Publishing Ag, Cham, pp 39-56

Ferraro PJ, Hanauer MM, Miteva DA, Canavire-Bacarreza GJ, Pattanayak SK, Sims KRE (2013) More strictly protected areas are not necessarily more protective: evidence from Bolivia, Costa Rica, Indonesia, and Thailand. Environ Res Lett. https://doi.org/10.1088/1748-9326/8/2/025011

Food and Agriculture Organization (2020) Global forest resources assessment 2020_key findings, Rome, Italy. https://doi.org/10.4060/ca8753en. Accessed June 2021

GBIF.org (2020) Global Biodiversity Information Facility (GBIF) occurrence download. https://doi.org/10. 15468/dl.gblnob. Accessed 07 Mar 2020

Geldmann J, Barnes M, Coad L, Craigie ID, Hockings M, Burgess ND (2013) Effectiveness of terrestrial protected areas in reducing habitat loss and population declines. Biol Conserv 161:230-238. https:// doi.org/10.1016/j.biocon.2013.02.018

Geldmann J, Manica A, Burgess ND, Coad L, Balmford A (2019) A global-level assessment of the effectiveness of protected areas at resisting anthropogenic pressures. Proc Natl Acad Sci U S A 116:2320923215. https://doi.org/10.1073/pnas.1908221116

Gonzalez-Maya JF, Viquez RL, Belant JL, Ceballos G (2015) Effectiveness of protected areas for representing species and populations of terrestrial mammals in Costa Rica. PLoS ONE 10:e0124480. https:// doi.org/10.1371/journal.pone.0124480

Guerry A, Polasky S, Lubchenco J, Chaplin-Kramer R, Daily G, Griffin R et al (2015) Natural capital and ecosystem services informing decisions: from promise to practice. Proc Natl Acad Sci 112:73487355. https://doi.org/10.1073/pnas.1503751112

Hansen AJ, DeFries R (2007) Ecological mechanisms linking protected areas to surrounding lands. Ecol Appl 17:974-988. https://doi.org/10.1890/05-1098

Hansen AJ, Davis CR, Piekielek N, Gross J, Theobald DM, Goetz S et al (2011) Delineating the ecosystems containing protected areas for monitoring and management. Bioscience 61:363-373. https://doi.org/ 10.1525/bio.2011.61.5.5 
Harris NC, Mills KL, Harissou Y, Hema EM, Gnoumou IT, VanZoeren J et al (2019) First camera survey in Burkina Faso and Niger reveals human pressures on mammal communities within the largest protected area complex in West Africa. Conserv Lett 12:e12667. https://doi.org/10.1111/conl.12667

Hockings M, Stolton S, Leverington F, Dudley N, Courrau J (2006) Evaluating effectiveness: a framework for assessing management effectiveness of protected areas, 2nd edn. IUCN, Gland, Switzerland and Cambridge, UK

Hockings M, Dudley N, Elliott W, Ferreira MN, MacKinnon K, Pasha M et al (2020) Editorial essay: Covid-19 and protected and conserved areas. Parks 26:7-24. https://doi.org/10.2305/IUCN.CH.2020. PARKS-26-1MH.en

Jones KE, Bielby J, Cardillo M, Fritz SA, O’Dell J, Orme CDL et al (2009) PanTHERIA: a species-level database of life history, ecology, and geography of extant and recently extinct mammals. Ecology 90:2648-2648. https://doi.org/10.1890/08-1494.1

Joppa LN, Bailie JE, Robinson JG (eds) (2016) Protected areas: are they safeguarding biodiversity? Wiley, Chichester, West Sussex, UK

Kamilar JM (2009) Environmental and geographic correlates of the taxonomic structure of primate communities. Am J Phys Anthropol 139:382-393. https://doi.org/10.1002/ajpa.20993

Kamilar JM, Beaudrot L, Reed KE (2015) Climate and species richness predict the phylogenetic structure of African mammal communities. PLoS ONE 10:e0121808. https://doi.org/10.1371/journal.pone.01218 08

Kark S, Tulloch A, Gordon A, Mazor T, Bunnefeld N, Levin N (2015) Cross-boundary collaboration: key to the conservation puzzle. Curr Opin Environ Sustain 12:12-24. https://doi.org/10.1016/j.cosust.2014. 08.005

Kembel SW, Cowan PD, Helmus MR, Cornwell WK, Morlon H, Ackerly DD et al (2010) Picante: R tools for integrating phylogenies and ecology. Bioinformatics 26:1463-1464. https://doi.org/10.1093/bioin formatics/btq166

Kukkala A, Maiorano L, Thuiller W, Arponen A (2019) Identifying national responsibility species based on spatial conservation prioritization. Biol Conserv 236:411-419. https://doi.org/10.1016/j.biocon.2019. 05.046

Kumar S, Stecher G, Suleski M, Hedges SB (2017) TimeTree: a resource for timelines, timetrees, and divergence times. Mol Biol Evol 34:1812-1819. https://doi.org/10.1093/molbev/msx116

Lacher TE, Davidson AD, Fleming TH, Gómez-Ruiz EP, McCracken GF, Owen-Smith N et al (2019) The functional roles of mammals in ecosystems. J Mammal 100:942-964. https://doi.org/10.1093/jmamm al/gyy 183

Laliberte E, Legendre P (2010) A distance-based framework for measuring functional diversity from multiple traits. Ecology 91:299-305. https://doi.org/10.1890/08-2244.1

Laliberté E, Legendre P, Shipley B (2014) FD: measuring functional diversity from multiple traits, and other tools for functional ecology. R package version 1.0-12. https://cran.r-project.org/web/packages/FD/ index.html

Lindsey PA, Alexander R, Frank LG, Mathieson A, Romañach SS (2006) Potential of trophy hunting to create incentives for wildlife conservation in Africa where alternative wildlife-based land uses may not be viable. Anim Conserv 9:283-291. https://doi.org/10.1111/j.1469-1795.2006.00034.x

Lindsey PA, Roulet PA, Romañach SS (2007) Economic and conservation significance of the trophy hunting industry in sub-Saharan Africa. Biol Conserv 134:455-469. https://doi.org/10.1016/j.biocon.2006.09. 005

Lindsey P, Allan J, Brehony P, Dickman A, Robson A, Begg C et al (2020) Conserving Africa's wildlife and wildlands through the COVID-19 crisis and beyond. Nat Ecol Evol 4:1300-1310. https://doi.org/10. 1038/s41559-020-1275-6

Maciejewski K, Kerley GIH (2014) Understanding tourists' preference for mammal species in private protected areas: is there a case for extralimital species for ecotourism? PLoS ONE 9:e88192. https://doi. org/10.1371/journal.pone.0088192

Martinez Arbizu P (2020) pairwiseAdonis: pairwise multilevel comparison using adonis. R package version 0.4. https://github.com/pmartinezarbizu/pairwiseAdonis

Maxwell SL, Cazalis V, Dudley N, Hoffmann M, Rodrigues ASL, Stolton S et al (2020) Area-based conservation in the twenty-first century. Nature 586:217-227. https://doi.org/10.1038/s41586-020-2773-z

Mazel F, Mooers AO, Riva GVD, Pennell MW (2017) Conserving phylogenetic diversity can be a poor strategy for conserving functional diversity. Syst Biol 66:1019-1027. https://doi.org/10.1093/sysbio/ syx 054

Mazel F, Pennell MW, Cadotte MW, Diaz S, Dalla Riva GV, Grenyer R et al (2018) Prioritizing phylogenetic diversity captures functional diversity unreliably. Nat Commun 9:2888. https://doi.org/10.1038/ s41467-018-05126-3 
McElwee P, Turnout E, Chiroleu-Assouline M, Clapp J, Isenhour C, Jackson T et al (2020) Ensuring a postCOVID economic agenda tackles global biodiversity loss. One Earth 3:448-461. https://doi.org/10. 1016/j.oneear.2020.09.011

Morrison JC, Sechrest W, Dinerstein E, Wilcove DS, Lamoreux JF (2007) Persistence of large mammal faunas as indicators of global human impacts. J Mammal 88:1363-1380. https://doi.org/10.1644/ 06-mamm-a-124r2.1

Muchapondwa E, Stage J (2015) Where to with institutions and governance challenges in African wildlife conservation? Environ Res Lett 10:095013. https://doi.org/10.1088/1748-9326/10/9/095013

Mukeka JM, Ogutu JO, Kanga E, Røskaft E (2019) Human-wildlife conflicts and their correlates in Narok County. Kenya Global Ecology and Conservation 18:e00620. https://doi.org/10.1016/j. gecco.2019.e00620

Munoz Brenes CL, Jones KW, Schlesinger P, Robalino J, Vierling L (2018) The impact of protected area governance and management capacity on ecosystem function in Central America. PLoS ONE 13:e0205964. https://doi.org/10.1371/journal.pone.0205964

Musila S, Monadjem A, Webala PW, Patterson BD, Hutterer R, De-Jong YA et al (2019) An annotated checklist of mammals of Kenya. Zool Res 40:3-52

Oberosler V, Tenan S, Zipkin EF, Rovero F (2020) Poor management in protected areas is associated with lowered tropical mammal diversity. Anim Conserv 23:171-181. https://doi.org/10.1111/acv. 12525

Ogutu JO, Piepho HP, Said MY, Ojwang GO, Njino LW, Kifugo SC, Wargute PW (2016) Extreme wildlife declines and concurrent increase in livestock numbers in kenya: what are the causes? PLoS ONE 11:e0163249. https://doi.org/10.1371/journal.pone.0163249

Ojwang GO, Wargute PW, Said MY, Worden JS, Davidson Z, Muruthi P et al (2017). Wildlife Migratory Corridors and Dispersal Areas: Kenya rangelands and Coastal Terrestrial Ecosystems, Nairobi, Kenya. http://www.kws.go.ke/content/launch-report-wildlife-corridors-and-dispersal-areas, Accessed 10 June 2020.

Oksanen J, Blanchet FG, Friendly M, Kindt R, Legendre P, McGlinn D et al (2019) vegan: Community ecology package. R package version 2.5-5. https://CRAN.R-project.org/package=vegan

Pacifici M, Di Marco M, Watson JEM (2020) Protected areas are now the last strongholds for many imperiled mammal species. Conserv Lett 13:e12748. https://doi.org/10.1111/conl.12748

Pärtel M, Szava-Kovats R, Zobel M (2013) Community completeness: linking local and dark diversity within the species pool concept. Folia Geobot 48:307-317. https://doi.org/10.1007/s12224-013-9169-X

Pavoine S, Ricotta C (2019) A simple translation from indices of species diversity to indices of phylogenetic diversity. Ecol Ind 101:552-561. https://doi.org/10.1016/j.ecolind.2019.01.052

Pianka ER (2011) Ecological niche. In: Evolutionary ecology, vol 7. HarperCollins Publishers, New York, pp 267-289

Pimm SL, Jenkins CN, Abell R, Brooks TM, Gittleman JL, Joppa LN et al (2014) The biodiversity of species and their rates of extinction, distribution, and protection. Science 344:1246752. https:// doi.org/10.1126/science.1246752

Rapacciuolo G, Graham CH, Marin J, Behm JE, Costa GC, Hedges SB et al (2019) Species diversity as a surrogate for conservation of phylogenetic and functional diversity in terrestrial vertebrates across the Americas. Nat Ecol Evol 3:53-61. https://doi.org/10.1038/s41559-018-0744-7

Republic of Kenya (2015) Fifth national report to the conference of parties to the convention on biological biversity. Nairobi, KE. https://www.cbd.int/doc/world/ke/ke-nr-05-en.pdf. Accessed 10 Feb 2020.

Riggio J, Kija H, Masenga E, Mbwilo F, Van de Perre F, Caro T (2018) Sensitivity of Africa's larger mammals to humans. J Nat Conserv 43:136-145. https://doi.org/10.1016/j.jnc.2018.04.001

Riggio J, Jacobson AP, Hijmans RJ, Caro T (2019) How effective are the protected areas of East Africa? Global Ecol Conserv 17:e00573. https://doi.org/10.1016/j.gecco.2019.e00573

Ripple WJ, Estes JA, Beschta RL, Wilmers CC, Ritchie EG, Hebblewhite M et al (2014) Status and ecological effects of the world's largest carnivores. Science 343:1241484. https://doi.org/10.1126/ science. 1241484

Rowan J, Kamilar JM, Beaudrot L, Reed KE (2016) Strong influence of palaeoclimate on the structure of modern African mammal communities. Proc R Soc B 283:20161207. https://doi.org/10.1098/ rspb.2016.1207

Safi K, Cianciaruso MV, Loyola RD, Brito D, Armour-Marshall K, Diniz-Filho JA (2011) Understanding global patterns of mammalian functional and phylogenetic diversity. Philos Trans R Soc Lond B Biol Sci 366:2536-2544. https://doi.org/10.1098/rstb.2011.0024

Saura S, Bertzky B, Bastin L, Battistella L, Mandrici A, Dubois G (2018) Protected area connectivity: shortfalls in global targets and country-level priorities. Biol Conserv 219:53-67. https://doi.org/ 10.1016/j.biocon.2017.12.020 
Saura S, Bertzky B, Bastin L, Battistella L, Mandrici A, Dubois G (2019) Global trends in protected area connectivity from 2010 to 2018. Biol Conserv 238:108183. https://doi.org/10.1016/j.biocon.2019. 07.028

Schmeller DS, Evans D, Lin Y-P, Henle K (2014) The national responsibility approach to setting conservation priorities-recommendations for its use. J Nat Conserv 22:349-357. https://doi.org/10. 1016/j.jnc.2014.03.002

Shaw RG, Mitchell-Olds T (1993) ANOVA for unbalanced data: an overview. Ecology 74:1638-1645. https://doi.org/10.2307/1939922

Soulé ME, Estes JA, Miller B, Honnold DL (2005) Strongly interacting species: conservation policy, management, and ethics. Bioscience 55:168-176. https://doi.org/10.1641/0006-3568(2005)055[0168:Siscpm]2.0.Co;2

Stevens RD, Cox SB, Strauss RE, Willig MR (2003) Patterns of functional diversity across an extensive environmental gradient: vertebrate consumers, hidden treatments and latitudinal trends. Ecol Lett 6:1099-1108. https://doi.org/10.1046/j.1461-0248.2003.00541.x

Stolton S, Redford KH, Dudley N (2017) The futures of privately protected areas. IUCN, Gland, Switzerland

Tack JD, Jakes AF, Jones PF, Smith JT, Newton RE, Martin BH et al (2019) Beyond protected areas: private lands and public policy anchor intact pathways for multi-species wildlife migration. Biol Conserv 234:18-27. https://doi.org/10.1016/j.biocon.2019.03.017

Thomas CD, Gillingham PK (2015) The performance of protected areas for biodiversity under climate change. Biol J Lin Soc 115:718-730. https://doi.org/10.1111/bij.12510

Tyrrell P, du Toit J, Macdonald D (2020) Conservation beyond protected areas: using vertebrate species ranges and biodiversity importance scores to inform policy for an east African country in transition. Conserv Sci Pract 2:e136. https://doi.org/10.1111/csp2.136

UNEP-WCMC, IUCN (2021a) Protected planet: the world database on protected areas (WDPA) and world database on other effective area-based conservation measures (WD-OECM). UNEP-WCMC and IUCN, Cambridge, UK. www.protectedplanet.net. Accessed Feb 2021

UNEP-WCMC, IUCN (2021b) Protected planet report 2020. Cambridge UK; Gland, Switzerland. https:// livereport.protectedplanet.net/. Accessed 21 June 2021.

Upham NS, Esselstyn JA, Jetz W (2019) Inferring the mammal tree: species-level sets of phylogenies for questions in ecology, evolution, and conservation. PLoS Biol 17:e3000494. https://doi.org/10.1371/ journal.pbio. 3000494

Veech JA (2018) Measuring biodiversity. In: Dellasala DA, Goldstein MI (eds) Encyclopedia of the anthropocene. Elsevier, Oxford, UK, pp 287-295. https://doi.org/10.1016/b978-0-12-809665-9.10296-4

Veldhuis MP, Ritchie ME, Ogutu JO, Morrison TA, Beale CM, Estes AB et al (2019) Cross-boundary human impacts compromise the Serengeti-Mara ecosystem. Science 363:1424-1428. https://doi.org/ 10.1126/science.aav0564

Venter O, Fuller RA, Segan DB, Carwardine J, Brooks T, Butchart SH et al (2014) Targeting global protected area expansion for imperiled biodiversity. PLoS Biol 12:e1001891. https://doi.org/10.1371/ journal.pbio.1001891

Venter O, Sanderson EW, Magrach A, Allan JR, Beher J, Jones KR et al (2016) Global terrestrial human footprint maps for 1993 and 2009. Sci Data 3:160067. https://doi.org/10.1038/sdata.2016.67

Villeger S, Mason NW, Mouillot D (2008) New multidimensional functional diversity indices for a multifaceted framework in functional ecology. Ecology 89:2290-2301. https://doi.org/10.1890/07-1206.1

Watts ME, Stewart RR, Martin TG, Klein CJ, Carwardine J, Possingham HP (2017) Systematic conservation planning with Marxan. In: Gergel SE, Turner MG (eds) Learning landscape ecology: a practical guide to concepts and techniques. Springer New York, New York, pp 211-227. https://doi.org/10. 1007/978-1-4939-6374-4_13

Webb CO, Ackerly DD, McPeek MA, Donoghue MJ (2002) Phylogenies and community ecology. Annu Rev Ecol Syst 33:475-505. https://doi.org/10.1146/annurev.ecolsys.33.010802.150448

Webb CO, Donoghue MJ (2005) Phylomatic: tree assembly for applied phylogenetics. Mol Ecol Notes 5:181-183. https://doi.org/10.1111/j.1471-8286.2004.00829.x

Weisberg JFAS (2019) An R companion to applied regression. Sage Publications, Thousand Oaks, CA

Western D, Musyoki C, Mwangi E, Mwachala G, Said M, Wargute P et al (2015) Kenya's natural capital: a biodiversity atlas (9966-21-178-0). https://maps.biodiversityatlaskenya.org/documents/377. Accessed Dec 2020

Wicander S (2015) State governance of protected areas in Africa. Case studies, lessons learned and conditions of success. UNEP-WCMC, Cambridge, UK

Wilman H, Belmaker J, Simpson J, de la Rosa C, Rivadeneira MM, Jetz W (2014) EltonTraits 1.0: specieslevel foraging attributes of the world's birds and mammals. Ecology 95:2027-2027. https://doi.org/ 10.1890/13-1917.1 
Wood SN (2011) Fast stable restricted maximum likelihood and marginal likelihood estimation of semiparametric generalized linear models. J R Stat Soc Ser B 73:3-36. https://doi.org/10.1111/j.1467-9868. 2010.00749.x

Publisher's Note Springer Nature remains neutral with regard to jurisdictional claims in published maps and institutional affiliations.

\section{Authors and Affiliations}

\section{Kenneth Otieno Onditi ${ }^{1,2,3,4} \mathbb{D} \cdot$ Xueyou $\mathrm{Li}^{1} \cdot$ Wenyu Song ${ }^{1,2} \cdot$ Quan $\mathrm{Li}^{1}$. Simon Musila ${ }^{3,4}$. James Mathenge ${ }^{5}$. Esther Kioko ${ }^{3,4}$. Xuelong Jiang ${ }^{1,4}$}

1 State Key Laboratory of Genetic Resources and Evolution, Kunming Institute of Zoology, Chinese Academy of Sciences, Kunming, China

2 Kunming College of Life Sciences, University of Chinese Academy of Sciences, Kunming, China

3 Department of Zoology, National Museums of Kenya, Nairobi, Kenya

4 Sino-Africa Joint Research Centre, Chinese Academy of Sciences, Nairobi, Kenya

5 Kenya Wildlife Service, Nairobi, Kenya 